\title{
Acetylator phenotypes in Papua New Guinea
}

\author{
R J A PENKETH*, S F A GIBNEY†, G T NURSE†, AND \\ D A HOPKINSON+
}

From*University College Hospital Medical School, London; $\uparrow$ Papua New Guinea Institute of Medical

Research; and $\ddagger$ MRC Human Biochemical Genetics Unit, London.

SUMMARY Acetylator phenotypes have been determined in 139 unrelated subjects from the hitherto untested populations of Papua New Guinea, and their relevance to current antituberculous isoniazid chemotherapy is discussed.

Several drugs, including isonicotinyl hydrazide (isoniazid), diamino diphenyl sulphone (dapsone), hydralazine, and some sulphonamides, are metabolised by the liver enzyme acetyl transferase. There is individual variation in the rate at which acetylation occurs and two phenotypes, rapid and slow, are usually recognised, which show an autosomal dominant mode of inheritance. The rapid phenotype includes subjects homozygous and heterozygous for an allele which determines a rapid rate of acetylation. The slow phenotype comprises subjects homozygous for an allele which determines slow acetylation of these drugs. Populations vary in the frequency of rapid and slow acetylators; for instance, the incidence of the slow type may be as low as 5 to $10 \%$ in Japanese and Eskimos but up to about $60 \%$ in some European, African, and Asiatic Indian populations. ${ }^{1-3}$

This paper describes the investigation of the acetylator status of 139 Papua New Guineans carried out during a 10 -week period of laboratory and field work. Our objective was to assess the population incidence of the acetylator phenotypes in a hitherto untested population, and to evaluate the relevance of the phenotypes in the control of tuberculosis. The acetylator polymorphism is relevant in as much as isoniazid, in combination with other drugs, is the mainstay of antituberculous therapy in Papua New Guinea, as in other parts of the world.

Slow acetylators are more likely to develop peripheral neuropathy on prolonged treatment with isoniazid, ${ }^{4}$ though this is preventable by pyridoxine supplementation, and rapid acetylators respond less well to a once weekly antituberculous regimen of isoniazid and companion drugs. ${ }^{15-7}$

Received for publication 12 May 1982.

\section{Materials and methods}

Subjects were drawn from hospital wards and from various educational institutions where exact conformity with the protocol of the test could be guaranteed. The largest single geographical sample came from the Southern Highlands Province and consisted of 33 subjects tested in the provincial capital Mendi. There were 47 subjects from the other Highland provinces, Enga, Western Highlands, Chimbu, and Eastern Highlands, collected mainly in Goroka, and 32 from the coastal provinces, East and West Sepik, Madang, Morobe, Central, Gulf, and Western. Of those from the island provinces three came from Manus, two from New Ireland, nine from East and West New Britian, and 11 from the North Solomons. These regions are shown in fig. 1.

Tests were carried out as recommended by Evans ${ }^{8}$ using blood and urine samples. Subjects took standard doses of sulphadimidine $500 \mathrm{mg}$ if they weighed less than $50 \mathrm{~kg}$, and $750 \mathrm{mg}$ if their weight exceeded $50 \mathrm{~kg}$, after an overnight fast. Drinking was not restricted, but to ensure rapid absorption the subjects were asked not to eat for 2 hours following the dose.

\section{Results}

The results are shown in the table and are plotted graphically in fig 2 to show the clear separation between the slow and rapid acetylators. There is a striking contrast in the incidence of acetylator phenotypes between the mainland of Papua New Guinea and the North Solomon Islands.

The slow acetylator allele was identified with a frequency of $0.798 \pm$ SE 0.121 in the North Solomons and $0.353 \pm$ SE 0.168 in East New Britain and not at all in the mainland population. 
TABLE Acetylator phenotypes of 139 Papua New Guineans from six different geographical areas.

\begin{tabular}{|c|c|c|c|c|c|}
\hline \multirow[t]{2}{*}{ Province } & \multirow[t]{2}{*}{ No of subjects } & \multicolumn{2}{|c|}{ Rapid acetylators } & \multicolumn{2}{|c|}{ Slow acetylators } \\
\hline & & Plasma & Urine & Plasma & Urine \\
\hline $\begin{array}{l}\text { Highland Provinces } \\
\text { Coastal Provinces } \\
\text { Manus Island } \\
\text { New Ireland } \\
\text { New Britain } \\
\text { North Solomons }\end{array}$ & $\begin{array}{r}83 \\
31 \\
3 \\
2 \\
9 \\
11\end{array}$ & $\begin{array}{l}72 \cdot 7(80) \\
70 \cdot 4(29) \\
75 \cdot 1(3) \\
74 \cdot 2(2) \\
67 \cdot 4(8) \\
61 \cdot 3(4)\end{array}$ & $\begin{array}{l}88 \cdot 9(81) \\
87 \cdot 9(30) \\
89 \cdot 0(3) \\
83 \cdot 6(2) \\
86 \cdot 6(8) \\
83 \cdot 2(4)\end{array}$ & $\begin{array}{l}- \\
\bar{Z} \\
\overline{15 \cdot 0(1)} \\
21 \cdot 7(7)\end{array}$ & $\begin{array}{l}- \\
- \\
\overline{59 \cdot 7(1)} \\
63 \cdot 5(7)\end{array}$ \\
\hline
\end{tabular}

Results expressed as mean percentage sulphadimidine acetylated in plasma or urine. Number of samples tested given in parentheses. Not all subjects were able to provide both a plasma and a urine sample and such cases were characterised on the basis of one result.

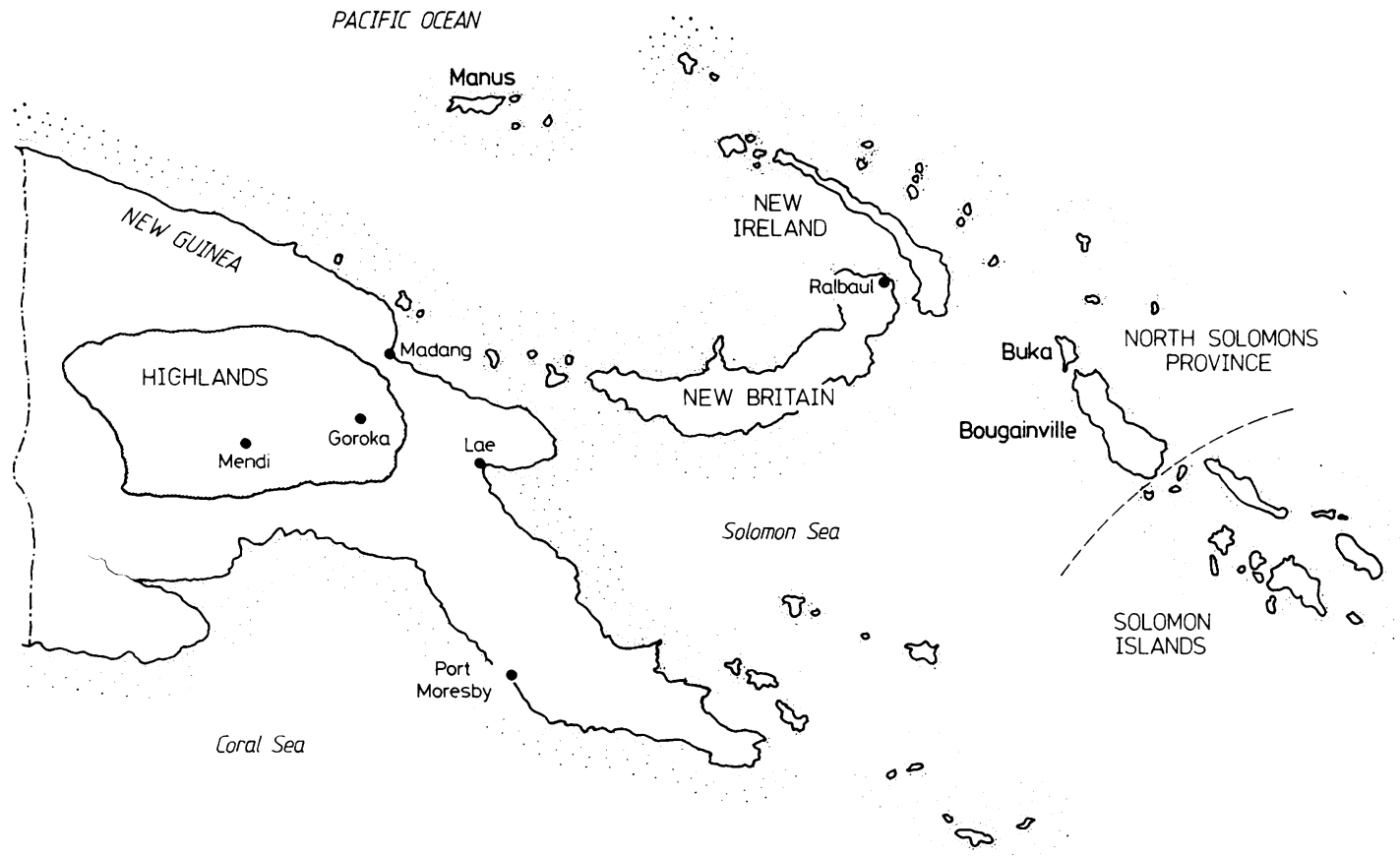

FIG 1 Geographical regions of Papua New Guinea from which specimens were collected.

However these estimates are based on relatively small population sample sizes, particularly in East New Britain.

\section{Discussion}

Failure of antituberculous chemotherapy during the maintenance phase of treatment may be attributed to lack of supervision and patient motivation. In principle, the problems may be overcome by supervised intermittent therapy with isoniazid and combinations of other antituberculous drugs. Such regimens have been evaluated in several centres and it has heen demonstrated that a good cure rate can be obtained in subjects of the rapid acetylator phenotype receiving twice weekly isoniazid and companion drugs. However, subjects of the slow acetylator phenotype could be maintained on once weekly dosage regimens to obtain a similar cure rate. Thus, in the communities where the health care system is favourable and both phenotypes are common, the acetylator status of each patient could be evaluated before the start of a supervised intermittent treatment regimen, as has been pioneered in urban communities in Czechoslovakia. ${ }^{7}$

Papua New Guinea is fortunate to have a health 


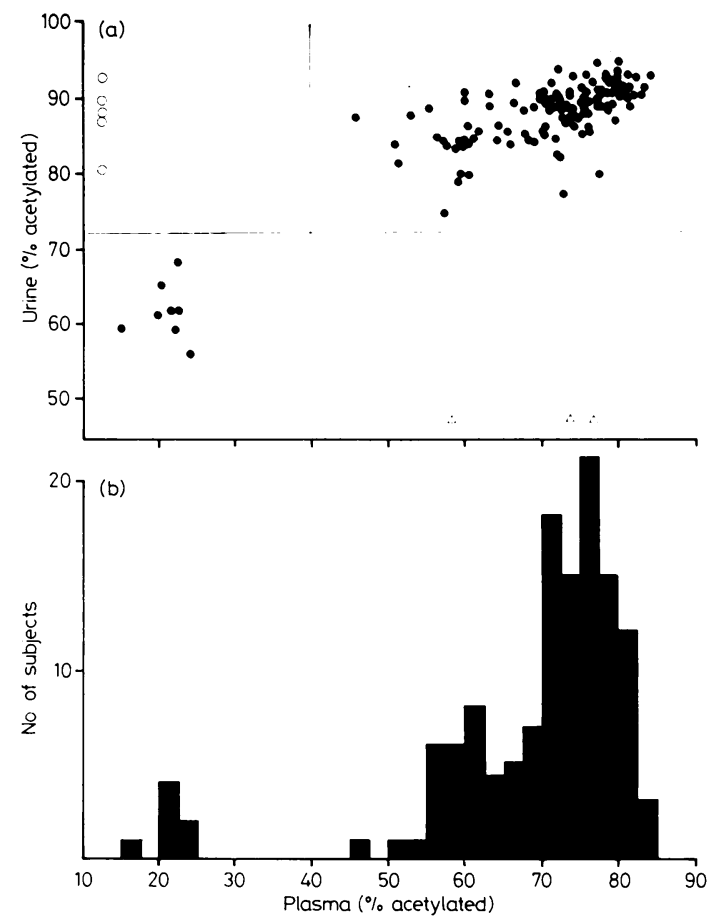

FIG 2 (a) Urine and plasma values for \% acetylated sulphadimidine in 139 subjects from Papua New Guinea. Open circles indicate values in five subjects from whom only urine was tested and open triangles indicate subjects from whom only plasma was tested.

(b) Histogram of plasma values of $\%$ acetylated sulphadimidine in the 139 subjects.

care system consisting of several hospitals and several hundred aid posts each staffed by an orderly trained to recognise and treat or refer common diseases. These Aid Post Orderlies are backed by regular patrols, both from the nearby hospitals and by the Health Extension Officer responsible for the area. Health Extension Officers receive a 3-year training which contains most aspects of a medical course that are directly relevant to the common ailments in Papua New Guinea. Thus, most rural communities are within a few miles of an aid post. Following a diagnosis of tuberculosis, an 8-week period of intensive therapy (streptomycin $1 \mathrm{~g}$ im, $300 \mathrm{mg}$ isoniazid, $150 \mathrm{mg}$ thioacetazone daily) is started in hospital. The patients then go on to a maintenance regimen of twice weekly isoniazid, with pyridoxine supplementation, and streptomycin (im) administered at an aid post. An alternative maintenance regimen involves self administration of combined isoniazid-thioacetazone tablets daily, a supply being collected from an aid post every 4 weeks, but this is avoided wherever possible to ensure maximum supervision. ${ }^{9}$

We found only the rapid acetylator phenotype on the mainland of Papua New Guinea and the intermittent twice weekly isoniazid-streptomycin maintenance regimen seems appropriate here. In New Britain and the North Solomon Islands, however, a once weekly isoniazid-streptomycin maintenance regimen could be employed. Our results suggest that the slow acetylator phenotype could occur in as many as half the patients. The acetylator phenotype of each patient could easily be determined during the initial intensive therapy period in hospital, since coincident isoniazid does not affect the results of the sulphadimidine test. The rapid acetylators could then be allocated to the twice weekly and slow acetylators the once weekly isoniazid-streptomycin maintenance regimen.

The striking difference in the slow acetylator gene frequency between the people of the mainland of Papua New Guinea and the North Solomon Islanders (coupled with the unique physical appearance and colour of the latter) can be seen as further evidence of the individuality of the North Solomonese when compared with people from other provinces of Papua New Guinea. This is supported by the finding of an extremely high frequency $(0.413)$ of the phosphoglucomutase allele $P G M_{1}^{2}$ in Buka, the northernmost of the North Solomons, ${ }^{10}$ which is the highest frequency of this allele yet found in Melanesia. The discovery of the presence of the slow acetylator gene in the island of East New Britain provides evidence of genetic contact with the North Solomonese. There is little other evidence of this, though it is possible that the transferrin $T f^{\mathrm{D} 1}$ allele could have come via East New Britain to the North Solomons. ${ }^{10}$

Our investigation of the frequency of acetylator phenotypes in Papua New Guinea and the neighbouring island provinces was based on considerations of the antituberculous therapy practised in this area and in particular the efficacy of isoniazid in subjects of rapid phenotype. However, the recent reports of associations between acetylator status and other genetic markers such as the HLA type, and the development of a lupus-like syndrome after medication with drugs such as procainamide, ${ }^{11}$ hydralazine, and isoniazid suggests that the acetylator polymorphism may have wider pharmacological significance. The genetic factors involved in the manifestation of such side effects are complex and accurate identification of subjects at risk is likely to be a difficult practical problem. For example, the occurrence of the lupus-like syndrome seen in hypertensive patients treated with hydralazine 
appears to be associated with sex (female) and HLA type (DR4), as well as the acetylator type (slow). ${ }^{12}$

It will be noted that the distribution of the plasma values from the rapid acetylators (fig 2) is bimodal. Subjects showing the relatively higher proportions of acetylated sulphadimidine may represent homozygotes for the 'rapid' gene and the others with slightly lower values may be heterozygotes for 'rapid' and 'slow' genes.

Further testing using other drugs known to be acetylated by this system would perhaps establish the validity of this subdivision and lead to more accurate assessment of the genotype. We have assumed that the 'rapid' and 'slow' genes identified in this Papua New Guinea population are the same as those found in other populations throughout the world, However, it is conceivable that the acetylator polymorphism is, like many other genetic polymorphisms, rather heterogeneous and similar phenotypes may represent a wide range of diverse genotypic combinations owing to multiple allelism. Direct analysis of the structural gene or its gene product, acetyl transferase, will probably be necessary to resolve this question.

We are grateful to staff and students of the Mendi High School in the Southern Highlands Province, the Malaguna Technical College in East New Britain, the University of Papua New Guinea Medical School at Port Moresby, the Goroka Teachers College (UPNG) in the Eastern Highlands, and also the Health Extension Officers Training College at Madang for their co-operation in obtaining subjects for testing. We are also grateful to $\mathrm{Dr}$ G A Ellard for his advice, constructive criticism, and encouragement throughout this project. Mr Penketh received financial support from the Rodgers fund administered by the Medical Research Council, London, and also from the Trustees of the Bennington Memorial Studentship, University College London. $\mathrm{He}$ is also extremely grateful to a considerable number of people through- out Papua New Guinea for their help, advice, accommodation, transport, etc, without which this project would not have been possible.

\section{References}

1 Ellard GA. Variations between individuals and populations in the acetylation of isoniazid and its significance for the treatment of pulmonary tuberculosis. Clin Pharmacol Ther 1976;19:610-23.

2 Karim AKMB, Elfellah MS, Evans DAP. Human acetylator polymorphism: estimate of allele frequency in Libya and details of global distribution. $J$ Med Genet $1981 ; 18: 325-30$.

3 Weber WW, Hein DA. Clinical pharmacokinetics of isoniazid. Clin Pharmacokinet 1979;4:401-22.

4 Devadatta S, Gangadharam PRJ, Andrews RH, et al. Peripheral neuritis due to isoniazid. Bull WHO 1960;23: 587-98.

5 Tuberculosis Chemotheraphy Centre, Madras. A controlled comparison of a twice-weekly and three onceweekly regimens in the initial treatment of pulmonary tuberculosis. Bull WHO 1970;43:143-206.

6 Tuberculosis Chemotherapy Centre, Madras. A controlled comparison of two fully supervised once-weekly regimens in the treatment of newly diagnosed pulmonary tuberculosis. Tubercle 1973;54:23-45.

7 Fox W. The chemotherapy of pulmonary tuberculosis; a review. Chest 1979;76:785S.

8 Evans DAP. An improved and simplified method of detecting the acetylator phenotype. J Med Genet 1969;6: 405-7.

9 Health Extension Officer Handbook. Department of Health, Port Moresby, Papua New Guinea, 1979.

10 McLoughlin K, Blake NM, Hogen PF. Blood group, red cell enzyme and serum protein types in the Buka Islanders, Papua New Guinea. Hum Hered 1982;32:152-9.

11 Woosley RL, Drayer DE, Reidenberg MM, Neis AS, Carr K, Oates JA. Effect of acetylator phenotype on the rate at which procainamide induces antinuclear antibodies and the lupus syndrome. $N$ Engl J Med 1978;298:1157-9.

12 Batchelor JR, Welsh KI, Mansilla Tinoco R, et al. Hydralazine-induced systemic lupus erythematosus: influence of HLA-DR and sex on susceptibility. Lancet 1980 ;i:1107-9.

Requests for reprints to Dr D A Hopkinson, MRC Human Biochemical Genetics Unit, The Galton Laboratory, University College London, Wolfson House, 4 Stephenson Way, London NW1 2HE. 